\title{
JARDINES Y PATRONES DE AJARDINAMIENTO EN LAS URBANIZACIONES DEL LITORAL DE ALICANTE ${ }^{1}$
}

\author{
Álvaro Francisco Morote Seguido \\ María Hernández Hernández \\ Instituto Interuniversitario de Geografía. Universidad de Alicante \\ alvaro.morote@ua.es, maria.hernandez@ua.es
}

\section{RESUMEN}

El jardín es, junto a las piscinas, los dos elementos del exterior de la vivienda que han adquirido una mayor difusión en los modelos urbanos extensivos. Esta expansión se ha relacionado con la propagación de tipologías urbanas que buscan espacios urbanos menos densos y congestionados que los núcleos urbanos y con la proliferación de tipologías turístico-residenciales en espacios costeros. En el litoral de Alicante, los jardines privados se asocian a las urbanizaciones que se han ido configurando desde la década de 1960 a raíz de la expansión de la actividad turística de sol y playa y al turismo residencial. El objetivo de esta investigación es conocer las características principales de los jardines y los patrones de ajardinamiento que van a determinar la elección de un tipo u otro de jardín (atlántico o mediterráneo). El profundizar en el conocimiento de los factores culturales, sociales, económicos o ambientales que explican la elección de una tipología de jardín y de las especies que lo conforman resulta prioritario para determinar posibles repercusiones ambientales, como, por ejemplo, el consumo de agua tanto presentes como futuras.

Palabras clave: jardines, urbanización, litoral de Alicante, patrones de ajardinamiento.

Fecha de recepción: octubre 2013.

Fecha de aceptación: septiembre 2014.

1 Este artículo es resultado de la concesión de una beca pre-doctoral de Formación de Profesorado Universitario del Programa Nacional de Investigación Científica, Desarrollo e Innovación Tecnológica (FPU) y se inserta en el Proyecto de Investigación «Urbanización y metabolismo hídrico en el litoral de Alicante: análisis de tendencias para el periodo 2000-2010»(CSO2012-36997-CO2-02) financiado por el Ministerio de Economía y Competitividad. 


\section{ABSTRACT}

The garden is, next to the pools, the two outside elements of houses that have acquired a wider divulging in extensive urban models. This diffuseness has been associated with the enlargement of urban typologies that are looking for less dense and congested urban areas and the proliferation of tourist \& housing development typologies in coastal areas. On the coast of Alicante, private gardens are associated with housing development that has been configured since the 1960 as a result of the expansion of tourism activities related with sun and beach. The aim of this research is to know the main features of gardens and landscaping patterns that decide the choice of one or another type of garden (Atlantic or Mediterranean). Deepening the knowledge of cultural, social, economic or environmental factors that explain the choice of a type of garden and the species that constitute it is a priority to determine possible environmental impacts, as, for example, water demands in the future.

Keywords: gardens, housing development, coast of Alicante, landscaping patterns.

\section{INTRODUCCIÓN}

El Programa de Naciones Unidas para el Desarrollo (PNUD, 2000) estimaba que en el año 2015 un 55\% de la población mundial residiría en ciudades, por lo tanto, la aplicación de los principios de sostenibilidad en la gestión de las áreas urbanas es uno de los mayores retos que las políticas ambientales tienen planteados para el siglo XXI (Domene y Saurí, 2003). Esta premisa hay que tenerla en cuenta en amplios ámbitos del territorio europeo que han registrado desde mediados de los años ochenta un importante incremento de las áreas urbanizadas. El informe sobre el Estado del Medio Ambiente elaborado por la Agencia Europea de Medio Ambiente en 2002 (EEA, 2002) ponía de manifiesto que en los últimos veinte años la superficie edificada de Europa había crecido un $20 \%$. Alertando acerca de las repercusiones que esta dinámica podría tener sobre recursos como el agua o el suelo, las demandas energéticas o la generación de residuos. En un informe posterior, Urban sprawl (EEA, 2006), se insistía en la denominada expansión urbana; entendiendo por ello cuando la tasa de cambio del uso del suelo de rústico a urbano es superior a la de crecimiento demográfico de una determinada zona durante un período establecido. Este proceso, urbanización difusa, ha sido muy evidente en algunos ejes de crecimiento económico europeo como es el mediterráneo y en particular el español. Según los datos proporcionados por el Ministerio de Fomento, en el período 2001-2011, el número de viviendas visadas se elevaba a 5,6 millones, de las que un 55\% se concentraban en las regiones de Andalucía (1.115.659 viviendas), Cataluña (769.786), Comunidad Valenciana (791.882), Murcia (292.708) y Baleares (118.069) (Ministerio de Fomento, 2012). En el litoral mediterráneo español el incremento de la urbanización se inicia a partir de los 1960 y se vincula con el comienzo de la actividad turística de sol y playa en un primer momento y más recientemente con el boom inmobiliario. Este último periodo (desde mediados de los noventa hasta 2008) ha generado notables repercusiones territoriales que se insertan, en gran medida, en las dinámicas de cambio que han caracterizado a toda la costa mediterránea española (Hernández, 2013). 
La fuerte expansión de las funciones residenciales en el litoral mediterráneo ha ido asociada a la adquisición de viviendas por población procedente de otras regiones españolas; pero, sobre todo, por una fuerte demanda por parte de inmigrantes europeos (principalmente jubilados del centro y norte de Europa). En el periodo comprendido entre 2001 y 2011, la población, según el Censo de habitantes, aumentó en unos 6,09 millones; alcanzando a finales de 2011 los 46,8 millones (INE, 2012). Según el Padrón de Habitantes, en el año 2000, el porcentaje de población extranjera ascendía al 4,5\% del total nacional, elevándose al 12,1\% en 2011 (INE, 2012); dato que adquiere una mayor magnitud en la escala regional y local. En las provincias ribereñas del Mediterráneo, la población procedente del centro y norte de Europa jubilada o prejubilada se sitúa, salvo alguna excepción, en porcentajes superiores al $15 \%$ del total poblacional; alcanzando valores superiores al 50\% del total de la población extranjera en aquellas provincias en las que el desarrollo residencial (Baleares, Málaga y Alicante) se remonta a la década de los años setenta del siglo XX (Hernández et al., 2014). El análisis en la escala local refleja la intensidad de la llegada de población europea en la última década. Llamativos resultan municipios como Rojales, San Fulgencio o San Miguel de Salinas (sur de la provincia de Alicante) en los que el porcentaje de extranjeros ha pasado del 35 al $70 \%$ del total poblacional entre 2001 y 2011, respectivamente; ocupando los primeros puestos del ranking de municipios españoles con mayor número de extranjeros.

Los elementos externos de las viviendas (huertos, jardines y piscinas) se han interrelacionado profundamente con el proceso de urbanización, especialmente en las tipologías de baja o media densidad (chalés o viviendas adosadas, respectivamente) imitando el modelo anglosajón que, a menudo, incluye un jardín y piscina (Askew y McGuirk, 2004; Leichenko y Solecki, 2005). Los jardines se han convertido en uno de los elementos del exterior de la vivienda que más recursos hídricos consumen (Domene y Sauri, 2006) como consecuencia de instalación de praderas de césped o la introducción de formaciones vegetales de hoja caduca, que generan nuevas naturales urbanas (Swyngedouw, 1999). Es necesario, no obstante, hacer mención, por las repercusiones desde el punto de vista de la demanda de recursos hídricos, a la configuración de dos tipologías de jardín en función de la urbanización. Por un lado, se encuentran los jardines privados y unifamiliares de las urbanizaciones de chalés y, por otro, los comunitarios de las urbanizaciones de adosados y apartamentos. En el litoral alicantino, la gran mayoría de los primeros se encuentran en el litoral norte, mientras que en la costa sur destacan los asociados a los adosados.

Una de las afirmaciones más aceptadas desde la difusión de las ideas clorofílicas en las sociedades actuales es el hecho de que en el ámbito mediterráneo y durante las últimas décadas viene imponiéndose una cultura de jardín de clima húmedo que, según el modelo anglosajón, utiliza el césped como principal elemento ornamental. En cambio, las especies autóctonas, no gozan de un estatus similar y tienden a ser sustituidas por las de clima atlántico (Domene y Saurí, 2003). Así, nos encontramos con jardines de tipo «atlántico», especialmente en los hogares donde vive la clase social más acomodada a pesar de la mala adaptación de esta vegetación al clima mediterráneo debido a sus altas necesidades hídricas (Vidal et al., 2011). En esta región, los jardines de este tipo consumen aproximadamente 40 $\mathrm{hm}^{3} /$ año, lo que significa que la mitad del agua que se utiliza en el hogar en los meses de verano se destina para regarlo y más de un tercio del consumo anual de agua (Domene et al., 2005). Estos jardines, consiguientemente, pueden reestructurar radicalmente las relaciones 
entre la naturaleza-sociedad con la introducción de especies características de otras regiones (por ejemplo, el césped) en otras zonas climáticas (Parés et al., 2013).

La hipótesis de partida de esta investigación es corroborar si esta aseveración se cumple en todo el ámbito del litoral alicantino o influyen otros factores (sociales, económicos, culturales y psicológicos) en la elección del tipo de jardín. Componentes como el coste del agua puede ser un elemento de notable trascendencia a la hora de valorar las tipologías de jardín y las especies dominantes en ellos. Cuestión ésta que adquiere una mayor relevancia, si se relaciona con el tipo de agua (red pública de abastecimiento, pozo, tanque de pluviales, etc.), utilizado en su riego y el sistema manejado (manguera, regadera, riego por goteo, etc.), que determinan su eficiencia y, consiguientemente, el consumo final y el coste de su mantenimiento. El precio del agua parece jugar un papel importante en este proceso, ya que tienden a ser más influyentes en el exterior de la vivienda (jardín, piscina, etc.) que en el interior (Renwick y Archibald, 1998). Igualmente, son relevantes factores como la nacionalidad de los propietarios o su nivel educativo para explicar la elección de un tipo de jardín u otro. Conocer la nacionalidad del propietario resulta fundamental en el área de estudio dado la notable presencia de población extranjera, como se señaló en párrafos anteriores.

A pesar de la notable expansión de las tipologías urbanas extensivas y su influencia en la difusión de áreas ajardinadas, en las especies vegetales introducidas y en los sistemas de riego se sabe relativamente poco de este proceso y de las interacciones que se establecen entre los diferentes factores que determinan su elección. Además, existe la tendencia a pensar que los jardines privados están sujetos a unos aportes excesivos de agua generados por factores como la falta de experiencia o el bajo coste del recurso (Bauman et al., 1998). En España, faltan estudios empíricos sobre el gasto de agua por parte de los jardines privados y su incidencia en los consumos totales de los hogares (Domene y Saurí, 2003). En cambio, en el mundo anglosajón son numerosos los trabajos entorno a los jardines y sistemas de riego. Un ejemplo es un estudio realizado en el sur de California (Kiefer y Dzigieleski, 1991), también de clima mediterráneo, donde se mostró que aproximadamente el $60 \%$ de los propietarios de las viviendas encuestadas aplicaban menos agua que la necesitada realmente por las especies de sus jardines.

\section{OBJETIVOS Y METODOLOGÍA}

Atendiendo a la hipótesis de partida de este estudio, señalada en el epígrafe anterior, el objetivo de esta investigación es conocer la tipología y características principales de los jardines unifamiliares del litoral de Alicante y los patrones de ajardinamiento que influyen en la elección de un tipo u otro de jardín. Los jardines unifamiliares son uno de los elementos externos de las viviendas que menos se han estudiado en España. En este sentido, en otros países como Reino Unido, EE.UU. o Australia son numerosas las investigaciones que se han llevado a cabo en torno a esta temática. Por este motivo, se pretende con este artículo aumentar el conocimiento de las características de los jardines y, concretamente, para el litoral alicantino. Comprensión que resulta necesaria dada la notable difusión que han experimentado estas superficies asociadas a las nuevas tipologías urbanas ampliamente utilizadas en la última fase expansiva de la construcción. Ello nos permitirá comparar los resultados obtenidos con los de otros espacios mediterráneos y, por otro, poner de manifiesto el incremento de las demandas 
que éstos puedan ocasionar y, consiguientemente, la presión sobre los recursos hídricos. Nuevo uso que puede agravar los problemas de abastecimiento en áreas como el litoral de Alicante, donde la relación entre recursos disponibles y demanda es deficitaria. Un mayor conocimiento de los factores que determinan la elección de la tipología de un jardín, las especies dominantes, cuáles son las pautas de riego que adoptan sus propietarios, etc., pueden llegar a ser factores muy relevantes para contribuir a una mejor gestión de los recursos hídricos en este territorio.

La metodología utilizada para llevar a cabo esta investigación se ha basado en el trabajo de campo y en la realización de una encuesta dada la inexistencia de datos relativos a esta cuestión en estadísticas oficiales. La implementación de esta encuesta, diseñada por miembros del grupo de investigación Medio Ambiente y tecnologías de la información geográfica de la Universidad de Girona (García, 2012) en varias áreas del litoral mediterráneo español (Girona, Barcelona y Alicante) tenía como finalidad avanzar en el conocimiento de los jardines y de los patrones de ajardinamiento en un ámbito mediterráneo. Metodología que se utiliza también en esta investigación, ya que ambos territorios constituían las áreas de estudio de sendos proyectos de investigación financiados por el Ministerio de Ciencia y Tecnología y ejecutados entre el año 2009 y el 2012 por las universidades de Alicante, Autónoma de Barcelona y Girona (Urbanización y metabolismo hídrico en el litoral de Alicante: análisis de tendencias para el periodo 2000-2010»(CSO2012-36997-CO2-02).

\section{ÁREADE ESTUDIO}

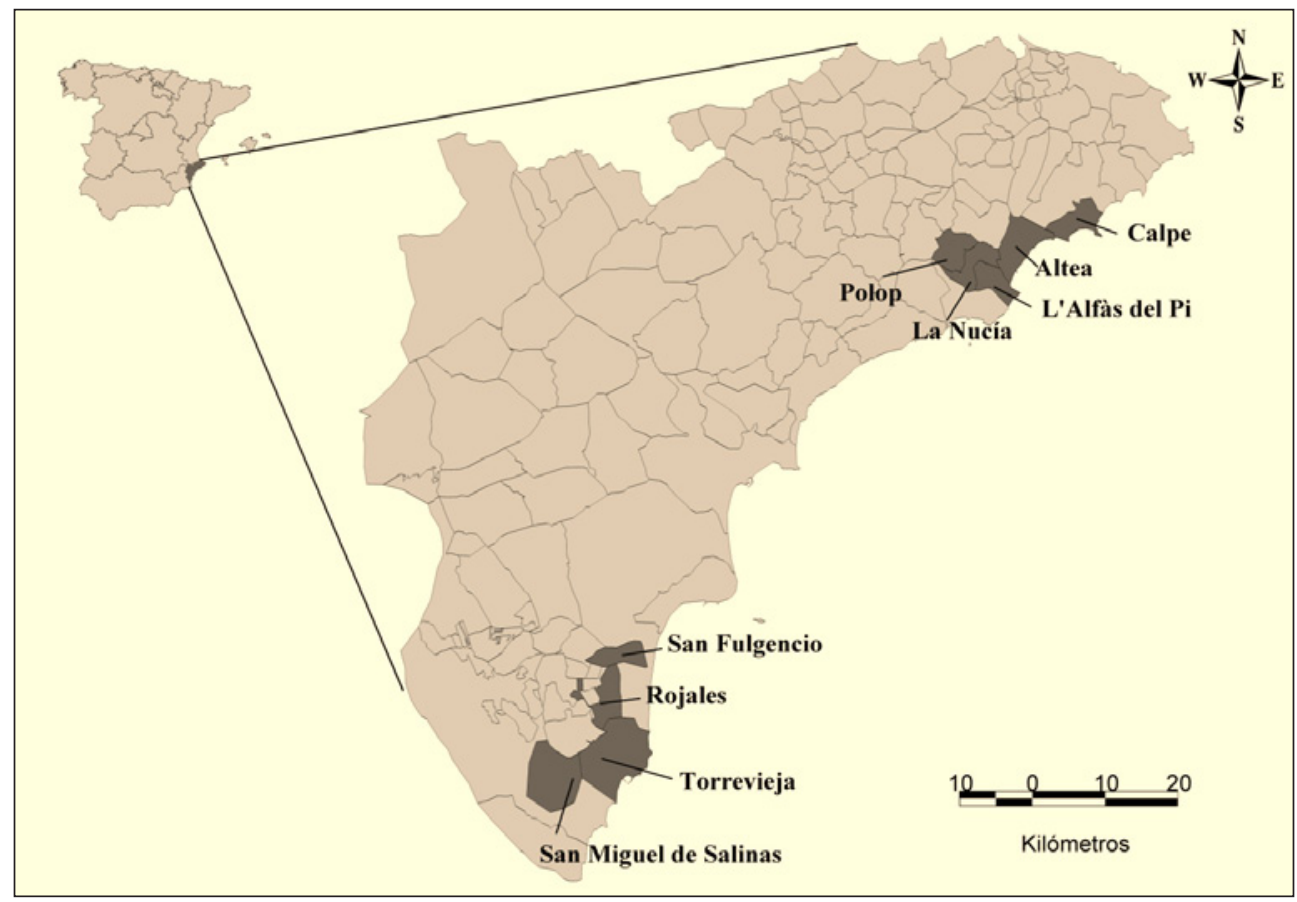

Elaboración propia a partir de la base cartografía extraída del Geoportal IDEE (Infraestructura de Datos Espaciales de España). 
Para escoger la muestra de viviendas a encuestar, se procedió en varias fases. En una primera, a partir de imágenes de satélite, se diferenciación los espacios urbanos que se clasifican como urbanizaciones, eliminado aquellos que corresponden a espacios urbanos compactos. Obtenida la cartografía, la siguiente tarea fue seleccionar los municipios de la muestra. Para ello, se tuvo en cuenta dos elementos, a saber, que fueran representativos de las diversas etapas de expansión urbano-residencial identificadas y que se adscribiesen a un modelo urbano-residencial de baja densidad. Atendiendo a ambos criterios se seleccionaron 9 municipios (5 en el litoral norte y 4 en el sur) (figura 1). En una tercera fase, se escogió la muestra aleatoria de las urbanizaciones y de los entrevistados. Ascendiendo aquélla a 28 urbanizaciones; siendo el número de cada municipio proporcional al número total de urbanizaciones existente en él y ajustada a las características definidoras del proceso urbanizador (tamaño de la urbanización, año de implantación y evolución temporal). Con respecto a las entrevistas realizadas, su número fue también distribuido en relación a la población total de cada municipio y de la urbanización seleccionada. Obteniéndose una ratio de éxito de un $30 \%$, es decir, para las 130 entrevistas realizadas entre mayo y julio de 2011 se llevaron a cabo unos 430 intentos. De esas 130 encuestas, se desestimaron 8, por motivos varios (incompletas, errores en los valores indicados, etc.).

La encuesta se articuló en seis apartados diferenciando entre aspectos generales de los propietarios, características de la vivienda, elementos del exterior del hogar, características del jardín, variables de comportamiento y consumo de agua. Los datos utilizados para esta investigación han sido los relativos a las características principales de los propietarios de los chalés (rasgos socio-demográficos), los atributos de las parcelas (tamaño, elementos que la integran) y las características del jardín (cuadro 1).

Cuadro 1

SIINTESIS DE LAS VARIABLES ANALIZADAS EN LA ENCUESTA

\begin{tabular}{|l|l|}
\hline $\begin{array}{l}\text { Rasgos socio-demográficos de los propietarios } \\
\text { de los chalés }\end{array}$ & $\bullet$ Edad \\
& - Nacionalidad \\
\hline Características de las parcelas & $\bullet \begin{array}{l}\text { Tamaño medio de la parcela } \\
\text { Tamaño medio del resto de elementos } \\
\text { (vivienda, jardín, zonas pavimentadas y } \\
\text { piscina) }\end{array}$ \\
\hline Características del jardín & $\bullet \begin{array}{l}\text { Tamaño medio } \\
\text { Tipología del jardín (niveles de complejidad) }\end{array}$ \\
& $\begin{array}{l}\text { Tipo de vegetación } \\
\text { Fuentes de suministro }\end{array}$ \\
& - Sistemas de riego \\
\hline
\end{tabular}

Elaboración propia.

Los datos que se han obtenido de estas encuestas han sido tanto cuantitativos, que han permitido su tratamiento estadístico, como cualitativos (respuestas y opiniones de los encuestados). De esta manera, se ha enriquecido la información cuantitativa derivada de su tratamiento estadístico, proporcionando detalles relevantes que permiten incrementar el 
conocimiento sobre los factores que inciden en la elección de un jardín, de sus niveles de complejidad o de las especies que lo integran. Especialmente relevantes son los relativos a los factores sociológicos y culturales que determinaban la elección de determinadas especies o las motivaciones que justificaban los cambios introducidos en los jardines en los últimos años.

\section{PATRONES DE AJARDINAMIENTO}

A la hora de estudiar las tipologías de los jardines es fundamental conocer los motivos por los que los propietarios deciden elegir un tipo u otro. En este sentido, cabe insistir que el proceso de expansión urbana significa un cambio en el modelo y la génesis de nuevas naturalezas urbanas (Hernández et al., 2014). Por ello, es necesario conocer cuáles son los factores que justifican las nuevas formas de ajardinamiento. Éstos son variados y se vinculan con causas diversas (económicas, sociológicas, psicológicas, culturales o climáticas) como pone de manifiesto la literatura científica al respecto. Para la consecución de los objetivos planteados y corroborar o negar la hipótesis de partida es necesario poner de manifiesto cuales son estos factores según la bibliografía y como éstos se implementan en el área de estudio a partir del resultado del análisis estadístico de las encuestas, el análisis de la evolución de los usos del suelo y el trabajo de campo.

El aumento del valor de la vivienda (Syme et al.,1980), la acentuación del sentimiento de pertenencia a un lugar (Sime, 1993), la realización de actividades vinculadas con el ocio y la recreación que puede contribuir al fomento de las relaciones entre los integrantes de la unidad familiar así como con los amigos y vecinos (Bhatti y Church, 2000), la manifestación del estatus social (Larsen y Harlan, 2006), el desarrollo de experiencias basadas en el contacto con la naturaleza así como la distracción de las preocupaciones personales cotidianas asociadas a su cuidado (Bhatti y Andrew, 2004) son algunas de las funciones que la literatura científica asigna a los espacios ajardinados. García (2012; 2013) afirma que, junto a estos factores, se debe tener, asimismo, en cuenta aquéllos (sociales, económicos y culturales) que determinan la elección específica de un jardín y, sobre todo, de su tipología y especies dominantes.

En relación con los factores socio-económicos cabe señalar la renta familiar y el precio del agua. Autores como Hurd (2006) afirman que el porcentaje de césped en el jardín varía en función del coste del agua, el nivel educativo y el grado de concienciación ambiental de los residentes. Por este motivo, cuanto más elevado es el valor del agua, más se reduce su superficie y se incrementa la ocupada por especies o elementos que no necesitan mucha dotación hídrica (macetas, plantas crasas o pavimentación del suelo) (García, 2012). El nivel de renta de los hogares influye, asimismo, en la tipología del jardín elegido, ya que se considera como un elemento que muestra el poder adquisitivo que tienen sus propietarios y su estatus social dentro de la comunidad (Larsen y Harlan, 2006; Larson et al., 2009). El aumento de los ingresos en el hogar repercute, asimismo, en una mayor variedad y número de plantas y la presencia de especies ajenas a las condiciones climáticas de ese ámbito territorial (Hope et $a l ., 2003)$. Estos patrones de ajardinamiento son corroborados en un estudio llevado a cabo por Domene y Saurí (2003) en la región metropolitana de Barcelona, donde el césped es el 
elemento vegetal dominante en los jardines de las viviendas de las familias más acomodadas, frente al predominio de vegetación mediterránea en las clases medias.

La relación entre nivel de ingresos y tipología de jardín es rebatida, sin embargo, por otros estudios. En este sentido, Mustafa et al., (2010) demostraron que la existencia de jardines con mayores necesidades hídricas no parecía aumentar de manera uniforme con los ingresos de los hogares. Su presencia se vinculaba a otros factores como los sociológicos y los culturales. Flack y Greenberg (2012), en esa misma línea, señalaron que en los hogares con mayor nivel educativo (que a su vez coinciden con los de mayor renta) se reduce el gasto de agua para riego, porque los residentes tienen una mayor concienciación medioambiental. Este aspecto se traduce, por ejemplo, en la elección de especies adaptadas al medio o la utilización de sistemas de riego más eficientes.

Por lo tanto, en relación con los factores socio-económicos se hallan estudios que ponen de manifiesto que cuanto mayor es la renta económica, mayor es el gasto del agua (presencia de césped y más dinero para invertir en el jardín que se plasma en mayor número y variedad de plantas). Pero también lo contrario, es decir, hay otras investigaciones que evidencian que a mayor renta económica y mayor nivel educativo, hay una mayor concienciación medioambiental y un sentido de la responsabilidad a la hora de ahorrar agua (Gregory y Di Leo, 2003; Syme et al., 2004). Relevantes resultan, asimismo, las interrelaciones que se establecen entre los factores sociológicos y los económicos. Existe una clara relación entre el nivel de riqueza del sector urbano donde se ubica el hogar y la diversidad de vegetación que se encuentra en el jardín. A mayor valor del $\mathrm{m}^{2}$ construido, mayor es la densidad y la variedad de especies vegetales que se pueden encontrar en un jardín. Las limitaciones económicas suponen también una traba para los propietarios a la hora de señalar sus preferencias en el tipo de jardín y su relación con el que disponen. La coincidencia entre ambos se observa únicamente en aquéllos con mayor renta disponible (Larsen y Harlan, 2006).

Un segundo factor a tener en cuenta es la ubicación del jardín en relación a la distribución espacial de la vivienda. Esta variable es más evidente en la parte más visible del jardín, es decir, el sector de acceso a la vivienda que además muestra el estatus social y la posición de los propietarios en la comunidad, en contraste con la zona trasera, más orientada al ocio y tiempo libre. Por lo tanto, los jardines que se sitúan en la parte delantera de la vivienda están compuestos por elementos y especies ornamentales que embellecen la panorámica de la vivienda; contribuyendo a un mayor consumo de agua para riego. En cambio, aquéllos que se sitúan en la parte posterior tienen un aspecto menos atractivo y una menor presencia de especies vegetales. Estas afirmaciones son corroboradas por una investigación llevada a cabo por Larsen y Harlan (2006) quienes pusieron de manifiesto la relación existente entre nivel de ingresos y el nivel educativo y la ubicación del jardín. En la parte delantera de la vivienda, los propietarios con los ingresos más bajos prefieren cierta presencia de césped, mientras que los de clase media optan por la vegetación autóctona y los de mayores ingresos escogen los de vegetación autóctona o, muy frecuentemente, los jardines con plantas y flores de colores brillantes y vegetación exuberante. En este último caso, la mayoría de las plantas son exóticas y su densidad crea un ambiente tropical, que, a su vez, requiere una mayor dotación hídrica diaria.

La antigüedad de la vivienda es un tercer elemento a tener en cuenta. Según Larsen y Harlan (2006), la edad de la casa es un indicador que determina el tipo de jardín predomi- 
nante en la parte delantera de la vivienda, pero no en el caso de la trasera. Igualmente es aquélla la que registra más cambios en su composición a lo largo del tiempo. Estos autores llegaron, asimismo, a la conclusión de que la probabilidad de la presencia de un jardín con alto porcentaje de césped coincidiendo con la fachada de la casa ha disminuido en los últimos años. Factores como el precio del agua o la concienciación ambiental puede ser una de las causas que explique este retroceso.

En relación con los aspectos familiares, un componente a destacar es la relación que se establece entre la tipología de jardín y la presencia de niños en la familia. En este sentido, Larson et al., (2009) argumentaron que los jardines xéricos pueden ser percibidos como potencialmente peligrosos para sus hijos debido a la existencia de especies con hojas coriáceas y espinosas. Consiguientemente, en los hogares donde hay niños pequeños, los progenitores, especialmente, las madres, valoran positivamente tener un jardín sin plantas crasas, ni cactáceas y con mucho césped. Existen, no obstante, otros estudios que no han demostrado una relación directa entre la presencia de niños y las formaciones vegetales mayoritarias (Hurd, 2006) y si, con el sexo de aquel que dedica más tiempo a las tareas de su mantenimiento. Un dato llamativo al respecto es que los hombres, en general, aprecian menos los jardines en comparación con las mujeres. Diferencias significativas se observan, asimismo, a la hora de establecer sus preferencias por el tipo de jardín elegido. Los primeros optan por los jardines con una estética que tienda hacia un carácter exuberante y silvestre, frente a las mujeres que eligen jardines cuidados y con abundancia de flores. La presencia de población jubilada es también en elemento a considerar (Nauges y Thomas, 2000). La disponibilidad de mayor tiempo libre permite dedicar más tiempo al cuidado del jardín, lo que favorece la existencia de estructuras más complejas y cuidadas. Sin embargo, una edad avanzada determina una limitación en las posibles tareas a llevar a cabo, la necesidad de contratar personas que las realicen con el consiguiente desembolso económico y, por tanto, hacia la simplificación de las estructuras ajardinadas y la elección de especies que requieran menor atención. En relación con los aspectos sociales también existe literatura científica que relaciona la tipología del jardín en función del lugar de procedencia o nacionalidad (Nauges y Reynaud, 2001). Éstos afirman que los jardines en el área de destino se llevan a cabo atendiendo a las características y las especies que se suelen plantar en sus lugares de origen.

Otro factor que puede condicionar los patrones de ajardinamiento son las variables psicológicas. Los residentes que tienen un mayor conocimiento sobre plantas muestran una mayor preferencia por la presencia de vegetación no autóctonas en su jardín (St. Hilaire et al., 2003), dada su mayor capacidad para cuidar de ellas y la menor dependencia de cuidados externos que encarecen su mantenimiento. Otros autores entre los que cabe mencionar a Yabiku et al., (2008) argumentaron que la socialización tiene efectos claros sobre las preferencias de ajardinamiento y, que éstos a su vez vienen determinados por los rasgos ambientales del territorio. Con este argumento, se podría pensar que la socialización determina que los individuos nacidos en ambientes áridos aprecien los jardines de tipo xérico con poca necesidad hídrica. Sin embargo, otros estudios han evidenciado el proceso contrario, que se manifiesta en la introducción de especies termófilas (olivos, por ejemplo) en ámbitos continentales o de tipo atlántico (césped) en los mediterráneos; dinámica favorecida por la consideración del jardín como un elemento que evidencia el estatus social del propietario y que se manifiesta en el mayor coste económico asociado a su mantenimiento e, indirectamente, mayor nivel de 
renta. Estas pautas de comportamiento, sin embargo, quedan condicionadas por los valores ambientales de los residentes (Kiesling y Manning, 2010), que influyen de manera significativa en la tipología de los jardines que se acaban implantando, dada la fuerte relación existente entre el nivel de concienciación ambiental y el compromiso de practicar una jardinería más adaptada a las condiciones ecológicas del territorio. Un último patrón de ajardinamiento son las condiciones climáticas, es decir, en función del clima, la tipología del jardín será una u otra. En este sentido las variables que cobran protagonismo son las precipitaciones y las temperaturas (Renwick y Archibald, 1998; Timmins, 2002; Hoffman et al., 2006).

\section{CARACTERÍSTICAS PRINCIPALES DE LOS JARDINES}

La reflexión epistemología acerca de la tipología de los jardines permite reflexionar sobre cuáles son los factores que determinan el tipo de jardín elegido (atlántico o mediterráneo) por el propietario de una vivienda; pero también sobre su estructura (niveles de complejidad) y las especies que lo integran. El análisis y tratamiento estadístico de los resultados de las encuestas realizadas en urbanizaciones de nueve municipios del litoral y prelitoral de Alicante (figura 1) permite poner de manifiesto su influencia en un área de estudio concreta; habilitando, asimismo, para determinar y ponderar, en su caso, el peso y la trascendencia de cada uno de ellos.

Es necesario para entender la relevancia de cada uno de ellos hacer una breve referencia a los rasgos socio-demográficos de los propietarios encuestados. Los resultados evidencian la elevada presencia de población extranjera procedente del centro y norte de Europa (75\% del total de la muestra). Estos datos, aunque elevados, son correctos, ya que como se comentó en la introducción el incremento de la población extranjera en estos municipios ha sido muy intenso en el último intercensal y, además, tienden a concentrarse en estos nuevos espacios urbanizados, en los cuales se ha llevado a cabo la encuestación. Destacan principalmente dos nacionalidades, los ingleses con un $40 \%$ de representación y los alemanes con el 12\%; datos validados igualmente al compararlos con la estadística oficial proporcionada por el Instituto Nacional de Estadística (INE). Significativo resulta, asimismo, el análisis de la edad de los residentes. El 65\% de la población tiene 60 años o más. Si se analiza este sector de población en función de la nacionalidad, la mayor parte de los extranjeros superan ese rango de edad. El 74\% de los ingleses y el 77\% de los alemanes tienen 60 años o más. En cambio, en la población española (el 25\% de la muestra), estos datos se invierten, ya que el $61 \%$ se encuentra en edad de trabajar (59 años o menos). Los rasgos socio-demográficos reflejan la estrecha relación que existe entre estos espacios urbanizados y la llegada de población extranjera europea jubilada. Interesante igualmente por la implicación en los patrones de ajardinamiento es el nivel educativo de las personas encuestadas. Los resultados de esta última variable ponen de manifiesto que los propietarios de las viviendas tienen un nivel de formación medio, medio-alto. El 52,3\% de los entrevistados tiene estudios secundarios y el $27,5 \%$, universitarios. Estos porcentajes medios encubren unas diferencias significativas si se analiza en función de la nacionalidad. El 55\% de los encuestados que han afirmado que tienen estudios de primer grado o no tienen estudios, corresponden con la población española. Cifras que contrastan con el 77,8 de extranjeros con estudios secundarios o universitarios. 
Los ítems incluidos en la encuesta y relacionados con el jardín han sido: el tamaño de la parcela y del jardín, tipología del jardín (niveles de complejidad), las principales especies vegetales que lo componen, la procedencia del agua utilizada y los diferentes sistemas de riego manejados. Análisis que se ha llevado a cabo en una doble escala. Por un lado, una general aplicable a todo el ámbito de estudio y, posteriormente, una segunda diferenciado entre los dos ámbitos en los que se ha subdividido el área de estudio (sector septentrional y meridional), dadas las diferencias puestas de manifiesto en el tratamiento estadístico de las encuestas.

\section{IV.1. El tamaño del jardín}

El análisis de ítems como «características de la parcela» y «características del jardín» tiene como objetivo conocer las dimensiones de las parcelas y de los jardines, al igual que los diferentes elementos que la integran y la tipología de los jardines para evidenciar la importancia creciente que adquieren los espacios exteriores de las viviendas en áreas donde la expansión urbana-residencial ha sido relevante.

Los valores obtenidos al analizar el ítem «características de la parcela» reflejan que nos encontramos ante propiedades de dimensiones pequeñas (el 35,30\% tienen $250 \mathrm{~m}^{2}$ o menos) o medianas (el $22,70 \%$ entre 251 y $500 \mathrm{~m}^{2}$ ). Las situadas entre $501-800 \mathrm{~m}^{2}$ y las de más de $800 \mathrm{~m}^{2}$, presentan valores en torno al $21 \%$ cada una de ellas. El valor medio de parcela de la muestra se sitúa en $678 \mathrm{~m}^{2}$. Las de $250 \mathrm{~m}^{2}$ o menos se localizan mayoritariamente en el litoral sur (el 77,43\%) y las de más de 500 metros, generalmente, en el litoral norte. Las afirmaciones anteriores quedan corroboradas al llevar a cabo un análisis más específico en las dos subáreas de estudio. En relación con los resultados obtenidos al comparar el litoral norte y sur, el tamaño de las parcelas asciende a $940 \mathrm{~m}^{2}$ en el litoral norte y a $416 \mathrm{~m}^{2}$ en el sur. Si tenemos en cuenta su distribución en $\mathrm{m}^{2}$, en el litoral norte las de $250 \mathrm{~m}^{2}$ o menos representan el 16,67\%, frente al 30\% que tiene más de $500 \mathrm{~m}^{2}$. En el litoral sur, estos datos se invierten pues las parcelas de $250 \mathrm{~m}^{2}$ o menos representan el $53,45 \%$, frente al $15,52 \%$ de más de $500 \mathrm{~m}^{2}$.

Cuadro 2

TAMAÑO DE LA PARCELA Y DE LOS ELEMENTOS QUE LA INTEGRAN EN EL ÁREA DE ESTUDIO

\begin{tabular}{|l|r|r|r|r|r|r|}
\hline \multirow{2}{*}{} & \multicolumn{2}{|c|}{ Litoral norte } & \multicolumn{2}{c|}{ Litoral sur } & \multicolumn{2}{c|}{ Total Ámbito de estudio } \\
\cline { 2 - 7 } & \multicolumn{1}{c|}{$\mathbf{m}^{\mathbf{2}}$} & \multicolumn{1}{c|}{$\boldsymbol{\%}$} & \multicolumn{1}{c|}{$\mathbf{m}^{\mathbf{2}}$} & \multicolumn{1}{c|}{$\boldsymbol{\%}$} & \multicolumn{1}{c|}{$\mathbf{m}^{\mathbf{2}}$} & \multicolumn{1}{c|}{} \\
\hline Edificio en planta & 177 & 18,86 & 130 & 31,27 & 153 & 25,06 \\
\hline Jardín & 376 & 40,04 & 171 & 41,18 & 274 & 40,61 \\
\hline Área pavimentada & 351 & 37,38 & 77 & 18,64 & 214 & 28,01 \\
\hline Piscina & 35 & 3,78 & 37 & 8,91 & 36 & 6,34 \\
\hline Total & $\mathbf{9 4 0}$ & $\mathbf{1 0 0 , 0 0}$ & $\mathbf{4 1 6}$ & $\mathbf{1 0 0 , 0 0}$ & $\mathbf{6 7 8}$ & $\mathbf{1 0 0 , 0 0}$ \\
\hline
\end{tabular}

Elaboración propia a partir de los datos proporcionados por el proceso de encuestación. 
En relación con el total del área de estudio, la superficie ocupada por el jardín en relación con la parcela representa el 40,61\% del total de la superficie, es decir, un poco más de la tercera parte de toda la parcela se destina a espacios ajardinados (cuadro 2). Si bien cabe destacar que este porcentaje ha disminuido en los últimos años en detrimento de la superficie ocupada por las áreas pavimentadas (el 28,01\%) que han visto aumentar su extensión y su importancia porcentual. Su incremento se vincula con el menor coste que supone su mantenimiento, ya que no deben adquirirse plantas y productos para su mantenimiento y, sobre todo, por la reducción del consumo de agua. Si se tiene en cuenta la superficie media del jardín, ésta ascendería para el total del área de estudio a $274 \mathrm{~m}^{2}$; dato a tener en cuenta dadas las repercusiones económicas y de consumo de recursos hídricos tanto desde el punto de vista de su implantación como de su mantenimiento. La mayoría de los jardines tienen una superficie media entre 51-250 $\mathrm{m}^{2}$ (el 42,21\%) (cuadro 3). Un porcentaje minoritario (el 8,34\%) corresponden a los que superan los $800 \mathrm{~m}^{2}$, que coinciden con las parcelas de mayores dimensiones del área de estudio que se encuentran en el litoral norte, mientras que los de menos de 50 $\mathrm{m}^{2}$, generalmente asociados a urbanizaciones de adosados, representan el 23,32\%. De éstos, un porcentaje mayoritario (el $58,82 \%$ ) se localiza en el litoral sur. Este dato adquiere una mayor trascendencia territorial, si se tiene en cuenta, además, que los jardines de los chalés se caracterizan por presentar unas dimensiones notablemente más reducidas que en el litoral norte (figura 2). Además, gran parte de su superficie está ocupada por la piscina y las zonas pavimentadas, mientras que la vegetación se reduce a algunos individuos aislados o a la presencia de macetas.

Cuadro 3

TAMAÑO DEL JARDÍN DEL ÁREA DE ESTUDIO

\begin{tabular}{|c|r|r|r|}
\hline Tamaño & Litoral norte (\%) & Litoral sur (\%) & Datos medios (\%) \\
\hline $\mathbf{5 0} \mathbf{~ m}^{\mathbf{2}} \mathbf{0}$ menos & 18,60 & 30,77 & 23,32 \\
\hline $\mathbf{5 1 - 2 5 0} \mathbf{~ m}^{\mathbf{2}}$ & 34,88 & 53,85 & 42,21 \\
\hline $\mathbf{2 5 1 - 8 0 0} \mathbf{~ m}^{\mathbf{2}}$ & 34,88 & 11,54 & 26,13 \\
\hline Más de $\mathbf{8 0 0} \mathbf{~ m}^{\mathbf{2}}$ & 11,63 & 3,85 & 8,34 \\
\hline
\end{tabular}

Elaboración propia a partir de los datos proporcionados por el proceso de encuestación.

El tamaño de la parcela va a repercutir en el del jardín: a menor parcela, menor superficie ocupada por el jardín. En este sentido, en el litoral norte tienen una superficie media de 376 $\mathrm{m}^{2}$. Mayor relevancia adquiere el hecho de que únicamente el 18,60\% ocupa una superficie de menos de $50 \mathrm{~m}^{2}$ frente al 46,5\% que tiene más de $251 \mathrm{~m}^{2}$. En el litoral sur, la superficie media de los jardines se reduce sensiblemente $\left(171 \mathrm{~m}^{2}\right)$. Pero más significativo, desde una óptica territorial, resulta su análisis por cohortes: el 30,77\% ocupan una superficie de $50 \mathrm{~m}^{2}$ o menos, el 53,85\% los que tienen entre 51-250 $\mathrm{m}^{2}$ y únicamente un 15,3\% tiene más de $251 \mathrm{~m}^{2}$.

La capacidad de renta de las familias es uno de los factores que determina la elección del tamaño de la parcela y del jardín; corroborando la trascendencia que los factores económicos tienen en los patrones de ajardinamiento. Si la renta familiar media disponible por habitante y año (es decir, la cantidad de que disponen las familias residentes para el consumo y el 
ahorro, una vez detraídas las amortizaciones o consumo de capital fijo en las explotaciones económicas familiares y los impuestos directos y cuotas satisfechas a la Seguridad Social) de la provincia de Alicante asciende, según el Atlas socio-comercial de la Comunidad Valenciana (Rovira, 2011), a 13.168€, los municipios del norte de la provincia mayoritariamente superan dicho umbral. Correspondiendo los valores más elevados (en torno a los 16.000€) a los municipios de L'Alfàs del Pi, Altea o La Nucía, es decir, aquellos en los que las parcelas son más amplias y donde la presencia de piscinas individuales es muy elevada y el tamaño de los jardines es mayor, frente al sur donde jardines y piscinas comunitarias o áreas pavimentadas presentan una mayor entidad. En los municipios del sur de la provincia, el umbral de renta es inferior a la media provincial. Observándose una diferencia interna entre aquellos en los que la intensa actividad urbanizadora ha incrementado esta renta hasta situarla en valores próximos o entorno a la media provincial (caso de municipios como Rojales, San Fulgencio o Torrevieja) frente a la mayoría donde ésta no supera los $12.000 €$. Esta capacidad de renta condiciona la tipología urbano-residencial dominante. La presencia de unifamiliares domina de manera abrumadora en el litoral norte, frente a tipologías de adosados y chalés en el sur; si bien en este último caso las parcelas son reducidas. Nos encontramos por tanto ante el predominio de población de clase media; si bien ésta presenta diferencias internas significativas desde el punto de vista de su nivel de ingresos entre el sector norte y sur provincial, que se plasma en la relación entre tamaño de la parcela y del jardín en relación a su capacidad de renta. A mayor nivel de ingresos, parcelas de dimensiones mayores y mayor superficie de jardín.

Figura 2

CHALÉS Y JARDINES EN EL LITORAL NORTE (IMAGEN IZQUIEDA-ALTEA) YEN EL LITORAL SUR (IMAGEN DERECHA-TORREVIEJA)

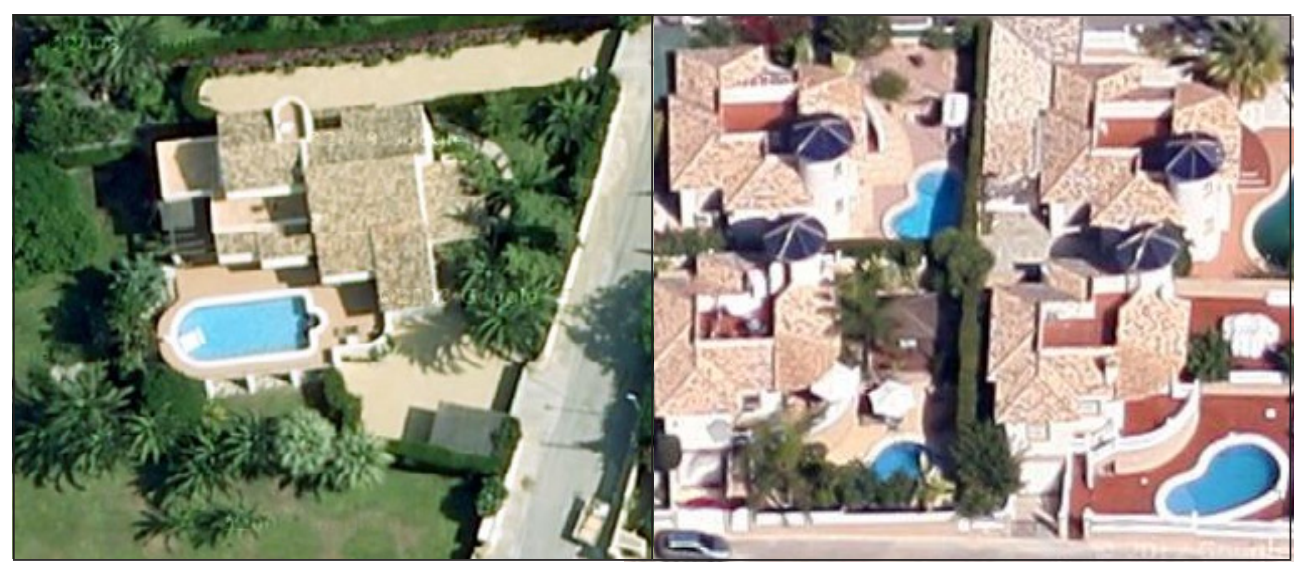

Fuente: https://maps.google.es/maps

\section{IV.2. Tipología del jardín}

En la tipología del jardín se analiza la complejidad de la estructura y la densidad de la vegetación. Con ello, se trata de valorar cuáles son los factores que explican el tipo de jardín elegido y cómo influyen en su estructura. Este ítem considera estrictamente la pre- 
sencia de los elementos y no la superficie ocupada por cada uno de ellos que será analizada en el apartado «tipo de vegetación». Se han distinguido entre los de un nivel (compuestos bien por césped, arbustos o árboles), los de dos (formados por césped y árboles, césped y arbustos o arbustos y árboles) y los de tres niveles (los que tienen césped, arbustos y árboles) (cuadro 4).

Cuadro 4

TIPOLOGÍA DE LOS JARDINES Y SU DISTRIBUCIÓN EN NIVELES DE COMPLEJIDAD

\begin{tabular}{|c|r|}
\hline & \multicolumn{1}{|c|}{$\%$} \\
\hline Un nivel & $\mathbf{4 0 , 2 1}$ \\
\hline Con césped & 9,78 \\
\hline Con arbustos & 20,65 \\
\hline Con árboles & 9,78 \\
\hline Dos niveles & $\mathbf{4 3 , 4 8}$ \\
\hline Césped más árboles & 1,09 \\
\hline Césped más arbustos & 0,00 \\
\hline Árboles más arbustos & 42,39 \\
\hline Tres niveles (césped más arbustos y árboles) & $\mathbf{1 6 , 3 0}$ \\
\hline
\end{tabular}

Elaboración propia a partir de los datos proporcionados por el proceso de encuestación.

La opción más frecuente es la de jardines de dos niveles (el 43,48\%), constituidos mayoritariamente por árboles y arbustos. Con valores próximos $(40,21 \%)$ se sitúan los que tienen un único nivel, principalmente compuestos por arbustos y en menor porcentaje por árboles. Únicamente el 9,78\% de los encuestados que han afirmado que tienen un jardín de un nivel es de césped. Son poco frecuentes $(16,30 \%)$ los que presentan la categoría de mayor complejidad (3 niveles). Ello es debido a la escasa presencia de césped, que dificulta alcanzar esos tres niveles de densidad. De manera general, en el 27,17\% de los jardines hay presencia de césped (en una de cada cuatro viviendas), pero éste porcentaje no significa que este elemento ocupe esa misma superficie en el jardín, sólo indica que sí hay presencia.

La elección de la tipología del jardín se relaciona con varios factores que interactúan entre ellos. Por un lado, con las condiciones climáticas del área de estudio (clima mediterráneo semiárido con temperaturas medias en torno a $\operatorname{los} 18^{\circ} \mathrm{y}$ precipitaciones inferiores a los $300 \mathrm{~mm}$ ) y los requerimientos hídricos de las especies y, por otro, con el consumo de agua y el precio del agua que inciden en su coste de mantenimiento. Éste factor, por último, se asocia con el nivel de renta de los propietarios. También la opción de las especies dominantes se adecúa a los factores citados. Entre las formaciones arbóreas, las de filiación mediterránea (adaptadas a una elevada evapotranspiración) como pinos y palmeras son predominantes. A éstas se une la presencia de los olivos, que si bien es un cultivo mediterráneo, tiene una amplia presencia como planta ornamental. Las formaciones arbustivas presentan también una clara filiación mediterránea. Dominan las plantas crasas (chumberas) y el matorral mediterráneo, donde a sus bajos requerimientos hídricos se une su carácter de especies fragantes. 
Los factores aducidos para su elección vienen determinados por los reducidos consumos hídricos, su relativo fácil mantenimiento y su encanto asociado a su carácter de vegetación perennifolia.

El nivel de renta no es, a priori, un factor esencial a la hora de elegir la tipología de jardín. Tanto en el sur como en el norte, a pesar de las diferencias de renta, los propietarios prefieren jardines xéricos y mediterráneos frente a los estrictamente atlánticos. Los argumentos asociados a esta elección se vinculan a factores climáticos (mayor adecuación), pero también a cuestiones económicas (coste de mantenimiento) y estéticas (estado de conservación). El coste de su mantenimiento (consumo de agua elevado asociado a su riego), pero también las tareas necesarias para su conservación y la dificultad de mantenerlo en buen estado en el periodo estival debido a las altas temperaturas justifican la reducida presencia del césped. Siendo, además, ésta la única superficie que presenta una tendencia negativa en los últimos cinco años. En esta línea, es significativo el hecho de que numerosos encuestados han sustituido el jardín con césped por zonas pavimentadas y macetas de flores. Siendo los argumentos esgrimidos la disminución de los consumos de agua y el ahorro de dinero, de esfuerzo y de tiempo en mantenerlo. El nivel de renta y, sobre todo, el tamaño de la parcela, si que determina, en cambio, la mayor presencia de especies vegetales (árboles) y sobre todo su densidad, frente al predominio de las macetas y los espacios pavimentados; mucho menos costosos de mantener. Consiguientemente, los jardines con mayor número de árboles y densidad se localizan en los municipios del litoral septentrional de Alicante.

Una notable trascendencia a la hora de elegir la tipología de jardín tienen los factores sociológicos y culturales. Rasgo evidente al analizar el ámbito de procedencia de los propietarios y, asociado a esto, sus patrones de vida. El predominio de habitantes del centro y norte de Europa determinaría, según la bibliografía científica, un predominio de jardines de tipología atlántica. Así, por ejemplo, si analizamos los jardines atendiendo a su procedencia (españoles o extranjeros) encontramos diferencias significativas. Así, por ejemplo, en relación con los jardines de un nivel, para el caso de los encuestados que han afirmado tener césped, la mayoría (el 77,78\%) son extranjeros. También, el 77,33\% de los encuestados que tienen un jardín de tres niveles son foráneos. Este valor, a pesar de que las gramíneas es una opción minoritaria, adquiere una mayor trascendencia, si tenemos en cuenta que un $75 \%$ de la población encuestada son extranjeros y, sobre todo, evidencia el valor de los patrones culturales. No obstante, el rasgo definidor sigue siendo la escasa entidad del césped como tipología de jardín en el área de estudio, a diferencia de otros ámbitos mediterráneos como el área metropolitana de Barcelona (Domene y Saurí, 2006).

El nivel cultural de la población y el proceso de socialización puede contribuir también a explicar la adopción de jardines de tipología mediterránea. El ítem «nivel educativo» refleja que nos encontramos con una población con un nivel de formación medio, medio-alto. El $52,3 \%$ de los encuestados tiene estudios secundarios y el 27,5\%, universitarios y por tanto, una mayor sensibilización ambiental (Mustafa et al.). El valor de este factor se acentúa si se incorpora un nuevo factor como es la socialización. Cuestión esta relevante si tenemos en cuenta que en estas urbanizaciones predominan los residentes extranjeros procedentes del centro y norte de Europa, donde hay una larga tradición de tener uno de tipo atlántico. El análisis de los comentarios cualitativos de los entrevistados pone de manifiesto que el jardín actual es resultado de un proceso de socialización. La mayoría de los propietarios han 
afirmado que en un primer momento instalaron uno con tipología mixta (dos o tres niveles) donde el césped aparecía con bastante frecuencia. Pero con el tiempo, el coste del mantenimiento era muy elevado debido a la necesidad de riego frecuente, además de requerirles mucha atención y, sin embargo, presentar un estado maltrecho parte del año. Estos factores unidos a la existencia de bloques de consumo que penalizaban los consumos elevados y el incremento del precio del agua desde finales de los años noventa han determinado su progresiva sustitución por vegetación más acorde con el clima mediterráneo (árboles o arbustos perennifolios o plantas crasas), bien con la pavimentación de parte de la zona ajardinada o la introducción de sectores con gravilla, que reducen la evapotranspiración. De este modo, los consumos se reducían notablemente. Ilustrativas de este proceso resultan afirmaciones como: «no riego el jardín porque tengo plantas crasas», «en España hace mucho calor para tener plantas de tipo atlántico» $\mathrm{o}$ «en el jardín tengo árboles y arbustos que sólo se riegan con el agua de la lluvia». También mencionan la introducción de las macetas como un elemento significativo en el jardín; argumentado que contribuyen a embellecer el jardín con el colorido de las flores y a la vez reducen notablemente el consumo de agua. Incluso algunos entrevistados, como situación extrema, mencionaban el abandono progresivo del jardín como consecuencia de los costes inasumibles derivados de su mantenimiento. Cuestiones económicas y de concienciación ambiental, sin olvidar, una cierta adaptación al ámbito territorial aparecían como razones para este cambio.

\section{IV.3. Tipo de vegetación}

El análisis de las especies vegetales guarda una estrecha interrelación con la tipología de jardín. Con su estudio, se pretende conocer la superficie ocupada en el jardín según el tipo de vegetación, y de esta manera poner de manifiesto cuáles son las variedades mayoritarias y determinar los factores que influyen en su elección.

En relación con las especies del jardín, se ha diferenciando entre plantas crasas, arbustos ornamentales, bancales de flores y césped. De manera general, la estructura de un jardín estándar de las viviendas donde se han llevado a cabo las encuestas se caracteriza por el predominio de las plantas crasas que ocupan una superficie aproximada del 33,77\% del total del jardín (figura 3). Los arbustos ornamentales (romero, tomillo, brezo, madroño, etc.), segunda formación desde el punto de vista de la superficie ocupada, representa el 29,23\% del total y suelen plantarse tanto de forma aislada, pero sobre todo agrupados, a modo de setos, con la finalidad de embellecer el jardín. En los pavimentados, aparecen plantados en macetas para, de este modo, disponer de vegetación ornamental en espacios sin tierra. Proceso este asociado a espacios ajardinados de dimensiones reducidas o bien a estrategias para disminuir los costes de mantenimiento y consumos hídricos. Los bancales de flores (geranios, margaritas, lirios, etc.), si bien el término bancal es exagerado, ya que en realidad corresponden mayoritariamente a plantas de ciclo anual en macetas, presentan una dinámica positiva en los últimos años. Este incremento y, sobre todo, su plantación en macetas se vincula a la mejorara de la eficiencia de riego, especialmente en su época de crecimiento y floración; pero no hemos de olvidar tampoco que proporcionan un gran colorido en espacios ajardinados de reducidas dimensiones. Con el porcentaje más bajo se encuentra el césped $(15,12 \%)$. En el epígrafe anterior se ha destacado que aproximadamente en uno de cada cuatro jardines había 
presencia de césped, pero si se analiza la representatividad de este elemento en relación con el resto de vegetación, sólo una sexta parte de estos jardines estaría ocupado por este tipo de vegetación atlántica. Las razones esgrimidas para esta escasa presencia se asocian a cuestiones socio-económicas y climáticas principalmente. Concretamente, a la mala adaptación al clima mediterráneo que determina elevados consumos hídricos y costes de mantenimiento altos y al tiempo, mucho mayor, que hay que dedicarle para su cuidado (riego, corte, fertilización, aireado, escarificado, resiembra, etc.), que al resto de especies vegetales. No hemos de olvidar tampoco que son población jubilada o prejubilada en un alto porcentaje. Por lo tanto, la presencia de niños es muy reducida y no se contemplaría a los jardines xéricos como potencialmente peligrosos. Si bien, es una formación que tradicionalmente se ha asociado a vegetación atlántica, en la actualidad existen especies de césped adaptadas a climas secos o subtropicales (césped de las Bermudas o gramilla, la grama americana, el césped bahía o el césped africano), así como la introducción del denominado césped artificial, que minimizan los consumos. Éstos, sin embargo, son testimoniales en el área de estudio.

Figura 3

TIPO DE VEGETACIÓN

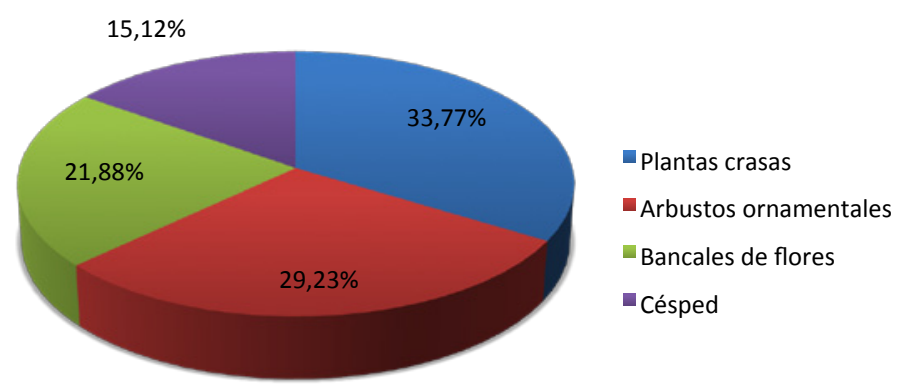

Elaboración propia a partir de los datos proporcionados por el proceso de encuestación.

Las principales formaciones vegetales de estos jardines están constituidas por plantas crasas y por arbustos ornamentales, que presentan una mejor adaptación a las condiciones climáticas de la región mediterránea. El factor ecológico se impone al cultural a través de un proceso de socialización, descrito en el epígrafe anterior; dinámica esta favorecida, asimismo, por cuestiones económicas vinculadas al elevado coste de mantenimiento del césped, frente a aquéllos en los que predominan plantas de filiación mediterránea.

\section{IV.4. Fuentes de abastecimiento de agua}

Los diferentes elementos del exterior de las viviendas, principalmente los jardines y las piscinas, son componentes que se han relacionado con un aumento notable del consumo de agua residencial en la periferia (Domene y Sauri, 2006), principalmente por los cambios en la producción de nuevas naturalezas, tales como la instalación de praderas de césped asociados con jardines de tipo atlántico (Swyngedouw, 1999). En esta línea, se enmarcan las preguntas relativas a las fuentes de suministro utilizadas en los diferentes elementos de la 
parcela (interior de la vivienda, jardín, piscina, huerto u otros usos) y sistemas de riego. Con ellas, se trata de conocer no sólo las fuentes de suministro, sino también si los propietarios adoptan sistemas alternativos a la red pública para el suministro o han incorporado medidas para minimizar los consumos. Los costes del agua parecen jugar un papel importante en este proceso, ya que tienden a ser más influyentes en el exterior de la vivienda (jardín y piscina) que en el interior (Renwick y Archibald, 1998). Resulta ilustrativo a la hora de abordar esta temática que la mayoría de los estudios realizados sobre las fuentes de abastecimiento en los jardines proceden de ámbitos anglosajones (García, 2012). Así, por ejemplo, según el Australian Bureau of Statistics (2006), el 11\% del agua que se consumía en los hogares de este país procedía de recursos propios del hogar (pozos y tanques pluviales). Loh y Coghlan (2003) en un estudio llevado a cabo en Sydney comprobaron que aquellas viviendas que tenían un pozo utilizaban menos agua de la red pública de abastecimiento que los que no disponían de él. También estos autores pusieron de manifiesto que los hogares de mayor renta económica tenían más pozos que las viviendas con renta más baja. Escasos resultan, en cambio, las investigaciones llevadas a cabo en el estado español. Domenech y Saurí (2011), aplicando un modelo hidráulico orientado a conocer las necesidades hídricas de los jardines y el tamaño óptimo de los tanques de pluviales llevado a cabo en el municipio de Sant Cugat del Vallès (Barcelona), llegaron a la conclusión de que en las casas unifamiliares, la capacidad de los tanques pluviales más eficientes para satisfacer la demanda de agua de riego era de $22 \mathrm{~m}^{3}$, y que este volumen óptimo permitía ahorrar el 61,7\% de la demanda de riego, equivalente a $42 \mathrm{~m}^{3} /$ año.

Los ítems contemplados en la encuesta sobre fuentes de abastecimiento en los jardines han sido: red pública de distribución, pozo con contador, pozo sin contador y tanque de aguas pluviales (figura 4). La mayoría de los encuestados (el 90,47\%) han afirmado que el agua que utilizan para el jardín proviene de la red pública de distribución, a pesar de que en ocasiones denuncian su mala calidad y los problemas de suministro (cortes en el suministro y caída de la presión). La presencia de pozos o tanques de pluviales es testimonial. Únicamente, un 6,72\% afirma que utiliza tanque de aguas pluviales y sólo el 2,80\% obtiene

Figura 4

FUENTES DE ABASTECIMIENTO DE AGUA
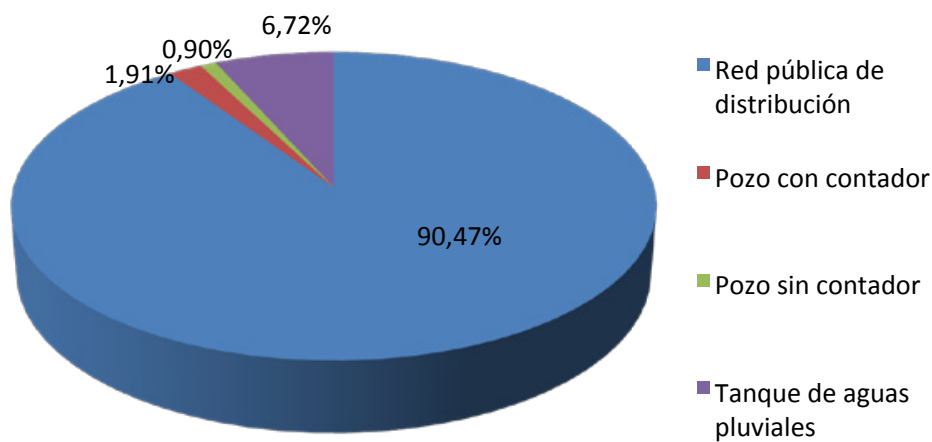

Elaboración propia a partir de los datos proporcionados por el proceso de encuestación. 
el agua de pozos. La elevada sobreexplotación de los acuíferos determina que su uso sea muy infrecuente dada la profundidad de éstos. Resulta, en cambio, llamativo que en una región semiáriada, donde la tradición en el uso de las pluviales es ancestral (aljibes, riegos de turbias, etc.), no se utilice como forma alternativa para regar los jardines. La presencia mayoritaria de población extranjera, con escaso conocimiento de estas tradiciones puede estar en el origen de este bajo porcentaje de uso. El elevado predominio de la red pública de abastecimiento condiciona el elevado coste que supone regar el jardín y, consiguientemente, las medidas para intentar contener su gasto, así como el predominio de jardines de tipología mediterránea, donde la adaptación de las plantas a las condiciones climáticas determina unos requerimientos hídricos menores.

\section{IV.5. Los sistemas de riego}

Los sistemas de riego son otro de los factores que pueden influir a la hora de establecer una tipología de jardín, dadas las interrelaciones que se establecen entre éstos y el tipo de especie dominante y su tamaño como consecuencia de sus diferentes necesidades hídricas y las posibilidades de ahorro asociadas a cada sistema. En numerosas ocasiones, se ha afirmado que los sistemas automáticos implican una mayor eficiencia en el riego y, consiguientemente, menores consumos. Igualmente a mayor consumo de la especie, mayor sería el ahorro. Sin embargo, numerosos estudios han rebatido dichas afirmaciones. Autores como Wentz y Gober (2007) han argumentado que en jardines con césped pero también en los xéricos, el coeficiente de ahorro de agua era menor del que se podía esperar. Las razones de este hecho podrían deberse a la creencia que tienen los residentes de que estos jardines ahorran agua y, consiguientemente, sus propietarios no ajustan los sistemas de riego automático en consonancia con los cambios en la evapotranspiración del jardín (St. Hilaire et al., 2003). Un comportamiento similar se observa en los que predominan las formaciones cespitosas. De manera general, los hogares con sistemas de riego más tecnificados utilizan más agua que aquéllos con sistemas de riego manuales (Syme et al., 2004). El motivo de este hecho es la tendencia a configurar los temporizadores para periodos más largos o con una mayor frecuencia de riego (García, 2012). Por tanto, a pesar de que se disponga de un sistema de riego tecnificado, la utilización de éste se hace durante un tiempo mayor, que si el riego es manual. Chesnutt y McSpadden (1991) afirmaron tras realizar una serie de estudios en diversos estados americanos que los sistemas de aspersión automático consumían de media 11,2\% más que aquellos hogares que utilizaban sistemas de aspersión manuales. Afirmación que se corroboró en una investigación llevada a cabo en el área metropolitana de Barcelona, donde se observó que aquellos hogares que poseían un sistema de riego por aspersión acostumbraban a tener un jardín con una mayor demanda de riego a causa de su asociación frecuente con la presencia de césped (Domene et al., 2005).

En esta investigación, se han diferenciado los siguientes elementos del jardín en relación con los sistemas de riego utilizados: el huerto (entendido como sustituto del jardín como espacio de ocio), las plantas crasas, los arbustos ornamentales, los bancales de flores, los árboles y el césped. Entre los sistemas de riego se encuentran la manguera, la regadera, el riego por goteo y por aspersión, tanto automático como manual. Del análisis de los resultados se deduce que la manguera es el método más utilizado para regar el jardín (cuadro 5); 
Cuadro 5

SISTEMAS DE RIEGO UTILIZADOS (\%)

\begin{tabular}{|l|r|}
\hline & \multicolumn{1}{|c|}{$\%$} \\
\hline Manguera & 38,14 \\
\hline Regadera & 14,41 \\
\hline Aspersor manual & 3,39 \\
\hline Aspersor automático & 11,02 \\
\hline Goteo manual & 5,08 \\
\hline Goteo automático & 27,12 \\
\hline No riega & 0,85 \\
\hline Total & 100,00 \\
\hline
\end{tabular}

Elaboración propia a partir de los datos proporcionados por el proceso de encuestación.

alcanzando valores próximos al 40\%. El predominio de jardines en los que dominan los arbustos y los arboles y con una presencia creciente de áreas pavimentadas convierte a este sistema en el más adaptado a estas tipologías, además de requerir escasas inversiones en su implantación y favorecer el ahorro de agua. Es asimismo el sistema predominante en el riego casi todos los tipos de vegetación del jardín, si exceptuamos el césped en que predomina el goteo automático (cuadro 6). El segundo sistema más utilizado es el goteo automático (el $27,12 \%$ ) y que se emplea principalmente para regar el césped, dados los mayores requerimientos hídricos y su mayor frecuencia de riego que determina la adopción de sistemas automáticos para regar y, al menos, teóricamente ahorrar agua. El resto de los sistemas tiene una implantación mucho menor en el área de estudio. Con valores medios entre el $10 \mathrm{y}$ el $15 \%$ aparece la regadera y el aspersor automático. Con valores testimoniales (por debajo del 5\%), se sitúa el goteo y el aspersor manual. La introducción de nuevos sistemas de riego como es el goteo y el aspersor se asocia a tecnificación y por tanto, con inversiones para su implantación. La necesidad de hacer frente a estos desembolsos económicos determina que se opte por este sistema frente al manual, ya que los costes no son muy diferentes, pero si el ahorro en tiempo.

Un número importante de propietarios, alrededor del 50\%, que han introducido cambios en los últimos 5 años en su jardín han apostado por la introducción de sistemas de manejo del riego (goteo o aspersión). Justifican su implantación por cuestiones de ahorro en el consumo, si bien reconocen que en ocasiones, y sobre todo en los primeros momentos de su instalación, han llegado a consumir más agua. Afirmación que corrobora el teórico ahorro de agua recogido por la bibliografía científica (Chesnutt y McSpadden; García, 2012; Syme et al., 2004). Su difusión se relaciona con su amplio uso en los espacios rurales aledaños, donde su introducción se remonta a los años ochenta vinculada a sistemas de modernización de regadíos o transformación de secanos en regadío mediante sistemas de manejo y ahorro de agua. A pesar del avance en la tecnificación en los sistemas de riego utilizados (goteo y aspersor) y de la creencia del ahorro de agua con la práctica de éstos, la mayoría de los propietarios siguen utilizando la manguera. Las razones esgrimidas para su uso se vinculan 
Cuadro 6

SISTEMAS DE RIEGO ASOCIADO A TIPOS DE VEGETACIÓN YAL HUERTO (\%)

\begin{tabular}{|l|r|r|r|r|r|r|}
\hline & Huerto & $\begin{array}{c}\text { Plantas } \\
\text { crasas }\end{array}$ & $\begin{array}{c}\text { Arbustos } \\
\text { ornamentales }\end{array}$ & $\begin{array}{c}\text { Bancales de } \\
\text { flores }\end{array}$ & Árboles & Césped \\
\hline Manguera & 43,75 & 40,00 & 40,20 & 32,00 & 38,00 & 30,00 \\
\hline Regadera & 6,25 & 14,00 & 19,50 & 20,70 & 14,40 & 10,00 \\
\hline Aspersor manual & 0,00 & 5,70 & 2,30 & 3,70 & 2,60 & 5,00 \\
\hline Aspersor automático & 25,00 & 8,50 & 6,80 & 7,50 & 9,20 & 10,00 \\
\hline Goteo manual & 6,25 & 2,80 & 4,50 & 7,50 & 5,20 & 5,00 \\
\hline Goteo automático & 6,25 & 28,50 & 26,40 & 28,30 & 30,20 & 40,00 \\
\hline No riega & 6,25 & 0,00 & 0,00 & 0,00 & 0,00 & 0,00 \\
\hline
\end{tabular}

Elaboración propia a partir de los datos proporcionados por el proceso de encuestación.

al tamaño del jardín que facilita su uso, el predominio de un número reducido de plantas, generalmente de porte arbóreo o arbustivo que fácilmente se riegan con la manguera, el coste derivado de la instalación del nuevo sistema de riego que no se compensa económicamente y la constatación de que, debido a una mala praxis o una mala programación, la eficiencia de estos sistemas no es tal e incluso pueden llegar a consumir más agua.

\section{CONCLUSIONES}

La expansión urbana-residencial en el litoral de Alicante y la instalación de jardines ha crecido espectacularmente desde las décadas de 1960 y 1970 y especialmente, coincidiendo con el último boom inmobiliario. Es necesario tener en cuenta la relación que se establece entre urbanización y espacios ajardinados para poder profundizar en el conocimiento de los rasgos que caracterizan a los modelos urbanos. Pero también lo es examinar los factores que explican la elección de una determinada tipología de jardín o las especies dominantes. Los jardines son uno de los elementos que se relacionan con el espectacular aumento de la urbanización de los últimos años, y que hay que tenerlos en cuenta, pues gran parte de los consumos de agua de las viviendas de estas urbanizaciones se producen en la parte exterior de los hogares. Un mejor conocimiento de éstos contribuirá a entender las dinámicas de demanda de agua y gestionar y planificar estos espacios, sobre todo, en el litoral de Alicante donde las urbanizaciones (principalmente de chalés) que fueron configurándose desde la década de 1960 han registrado desde mediados de los años noventa un espectacular crecimiento. La escasa bibliografía científica que al respecto existe sobre el litoral alicantino enfatiza el valor de los resultados derivados de la realización y tratamiento estadístico de la encuesta llevada a cabo. Si bien, es evidente que ésta presenta un universo reducido, un mejor conocimiento de estos elementos puede ayudar a gestionar y planificar los recursos disponibles en este territorio y sensibilizar a la población para una gestión más eficiente de éstos.

Teniendo en cuenta la literatura al respecto en relación con los factores que inciden en la tipología del jardín y los resultados obtenidos de las encuestas se pone de manifiesto que son varios y con peso diverso los patrones que influyen en la tipología de los jardines del 
litoral de Alicante. Los factores climáticos (radiación solar y escasez de precipitaciones), económicos (ingresos y precio del agua) resultan primordiales para entender los motivos que justifican la elección de un tipo de jardín. Éstos se complementan con motivaciones de tipo cultural (proceso de socialización), las sociales (edad, nivel educativo y área de procedencia) y las psicológicas (concienciación ambiental).

En relación con el nivel de renta, este factor influye en el tamaño de la parcela. Las parcelas más grandes y los espacios ajardinados de mayor superficie se localizan mayoritariamente en el litoral norte, que coincide con los municipios de mayor renta. En el norte, la parcela media tiene $940 \mathrm{~m}^{2}$ frente a los 678 en el litoral sur. Esta correlación, sin embargo, no es tan evidente con respecto a la tipología de jardín y más concretamente la presencia de césped. En el litoral de Alicante, a pesar de que las encuestas se llevaron a cabo en urbanizaciones donde residen habitantes con unos ingresos medios, medio-altos, el césped es un tipo de vegetación con presencia menor $(15,2 \%)$. Estas cifras contrastan con otros ámbitos mediterráneos como los jardines del área metropolitana de Barcelona donde el césped es la vegetación principal (el 48\%) en las urbanizaciones donde residen las familias de mayor renta (Domene y Saurí, 2003). No se cumple, o al menos, no es el factor determinante, como se recoge en gran parte de la literatura científica, de que a mayor renta, más presencia de especies con una mayor necesidad hídrica como es el caso del césped. Formación vegetal que evidencia el poder adquisitivo que tienen sus propietarios como afirma Larsen y Harlan (2006). El precio del agua, en cambio, resulta un factor muy relevante para entender tanto la tipología de jardín como las especies dominantes. Corroborando de este modo la tesis de Hurd (2006) quien sostenía que el porcentaje de césped en el jardín varía en función del coste del agua, a mayor valor, más se reducía su superficie. Su notable incremento en los últimos años, que sitúa a los municipios litorales de Alicante (precio medio de 2,16€ el metro cúbico) entre los más caros de España unido a la existencia de precios diferentes según tramos de consumo que penalizan un uso elevado, ha condicionado, por un lado, la presencia de especies con necesidades hídricas elevadas como es el césped y, por otro, los cambios que se introducen en el jardín para sustituir esas especies. El gasto derivado del riego y su mantenimiento explica la escasa presencia del césped. La tendencia mayoritaria es su sustitución por otras especies con menores requerimientos hídricos o la reducción del jardín por macetas y zonas pavimentadas. El precio del agua determina, por tanto, la tipología dominante de los jardines y la atención prestada a la aminoración de los consumo de agua. Numerosas han sido las opiniones de los encuestados al respecto. A modo de ejemplo cabe citar: «he reducido la presencia de césped por el incremento del precio del agua» $\mathrm{o}$ «he sustituido el césped por otras plantas que necesitaban menos agua». Estas motivaciones se complementan con aquellas que hacían referencia al menor tiempo destinado al mantenimiento del jardín.

Un segundo factor fundamental para comprender los patrones de ajardinamiento es el climático. Una elevada radiación solar y precipitaciones inferiores a los 300 milímetros anuales en el litoral sur de la provincia unido al elevado precio del agua explica el predominio de jardines de dos niveles (árboles y arbustos) y que las especies dominantes sean de filiación mediterránea, es decir, adaptadas a temperaturas elevadas y, sobre todo, precipitaciones escasas y concentradas en el tiempo. Igualmente, esa interrelación determina los cambios registrados en estos espacios en los últimos años. Algunas de las respuestas de los propietarios incidían en esta cuestión. Así indicaban que se sustituía el césped porque llovía poco 
o porque necesitaban regarlo todos los días y, a pesar de ello, su estado de conservación no era el más óptimo especialmente en los meses estivales. Las condiciones climáticas como señalaban Renwick, Timmins o Hoffman cobran protagonismo en los patrones de ajardinamiento del área de estudio. El peso de los factores físicos a la hora de elegir las especies vegetales que componen los jardines es mayor en los municipios litorales de Alicante que el registrado en territorios más húmedos como son Barcelona o Girona como corrobora la comparación de los resultados obtenidos en este estudio con los realizados en esas zonas por autores como Domene et al., (2005), Pares et al., (2013) o García (2013) o en ámbitos semiáridos de Estados Unidos o Australia, donde la presencia de vegetación atlántica es mayor como evidencian entre otras las publicaciones de Timmins (2002), St Hilari (2003), Loh (2003) o Larson (2009), entre otras.

Los patrones de ajardinamiento del litoral de Alicante vienen condicionados, por último, por factores sociales, psicológicos y culturales. La presencia mayoritaria de propietarios jubilados (el 65\%) determina que la presencia de niños es escasa. Por lo tanto, y teniendo en cuenta a Larson (2009), los propietarios no perciben los jardines xéricos como potencialmente peligrosos para sus hijos, ya que estos son adultos. Nos encontramos, por tanto, ante otro factor que apuntala el predominio de los jardines de tipología mediterránea; patrón que contrasta con autores como Nauges y Reynaud (2001) quienes afirmaban que la tipología del jardín se adecuaba a las características y especies de su área de procedencia. Hecho que no se observa en el área de estudio donde predominan los extranjeros procedentes del centro y norte de Europa (el 75\%). La elección de especies adaptadas al medio, la utilización de sistemas de riego más eficientes o la adopción de técnicas orientadas a la aminoración de su consumo se relaciona, coincidiendo con lo que señalan algunos autores, por ejemplo Flack y Greenberg (1987), con una mayor concienciación ambiental derivada ésta de su nivel educativo (medio; medio-alto). Algunos encuestados han argumentado que están muy concienciados con el ahorro de agua, como, por ejemplo, los que han citado que consumen poco gracias a la instalación de depósitos de pluviales, otros que suelen regar una vez por semana o los que aplican soluciones y sistemas en su vivienda para recoger toda el agua de lluvia posible para luego regar con ella. Sin embargo, su utilización es minoritaria, por no decir testimonial en el área de estudio. La mayoría menciona la adecuación de sus jardines a las condiciones de semiaridez. Los factores sociales se completan con los culturales; concretamente el proceso de socialización por el que la población ha ido adaptando sus jardines a las condiciones ecológicas de la zona. Esta dinámica de cambio es llamativa, teniendo en cuenta que es mayoritaria la población extranjera procedente de ámbitos más húmedo y donde ecológicamente predominan los jardines atlánticos. Este proceso es evidente al relacionarlo con la edad de las viviendas. Como señalaban Larsen y Harlan (2006) la presencia de césped es menor en aquellas viviendas más antiguas en gran medida porque son las que registran un mayor número de cambios en su configuración.

En el área de estudio, la consideración del césped como elemento ornamental por antonomasia de los jardines y asociado ésta a una imagen estereotipada del verde como elemento fundamental queda descartada por diversos factores como se comentó en párrafos precedentes. La hipótesis de que una presencia mayoritaria de población centroeuropea de áreas con pluviometrías más elevadas y donde el césped es predominante podría traducirse en una imitación de modelos de jardín propios de otros ámbitos territoriales no se cumple. En este 
sentido, esta población extranjera que ha comprado una vivienda en el litoral de Alicante, en un primer momento imita, en parte, la tipología del jardín de su área de procedencia, pero con el tiempo, una vez van conociendo las características climáticas y, sobre todo, el gasto en la factura del agua (ya que mantener un jardín de tipo atlántico en esta región es más costoso que en sus países de origen) deciden ir sustituyendo elementos como el césped por plantas crasas o las que más se adaptan a la región mediterránea (arbustos y árboles esclerófilos) o pavimentan parte del jardín para reducir los consumos hídricos.

\section{BIBLIOGRAFÍA}

AGENCIA EUROPEA DE MEDIO AMBIENTE (EEA) (2002): Señales medioambientales 2002. Referencias para el milenio. Copenhague. Agencia Europea del Medio Ambiente. Disponible en: http://www.eea.europa.eu/www/es/publications/environmental_assessment_report_2002_9-sum

AGENCIA EUROPEA DE MEDIO AMBIENTE (EEA) (2006): Urban sprawl in Europe. The ignored challenge. Informe $n^{o}$ 10/2006. Copenhague. Agencia Europea del Medio Ambiente. Disponible en: www.eea.europa.eu/publications/eea_report.../eea_ report_10_2006.pdf

AUSTRALIAN BUREAU OF STATISTICS (2006): Household Expenditure Survey. Disponible en: http://www.abs.gov.au/ausstats/abs@.nsf/mf/6530.0/

ASKEW, L.E. y McGUIRK, P.M (2004): «Watering the suburbs: distinction, conformity and the suburban garden». Australian Geographer, Vol. 35, 17-37.

BAUMANN, D.D.; BOLAND, J.J. y HANEMANN, W.M. (1998): Urban Water Management and Plannig. New York. McGraw Hill.

BHATTI, M. y ANDREW, C. (2004): «Home, the culture of nature and meanings of gardens in late modernity». Housing Studies, ${ }^{\circ} 19,37-51$.

BHATTI, M. y CHURCH, A. (2000): «I never promised you a rose garden: gender, leisure and home-making». Leisure Studies, ${ }^{\circ}$ 19, 37-51.

CHESTNUTT, T. y MCSPADDEN, C. (1991): A model-based evaluation of westchester water conservation program (1a ed.). San Diego: A\&N Technical Services.

DOMENE, E. y SAURÍ, D. (2003): «Modelos urbanos y consumo de agua. El riego de jardines privados en la Región Metropolitana de Barcelona». Investigaciones Geográficas, $n^{\circ} 32,5-17$.

DOMENE, E. y SAURÍ, D. (2006): «Urbanization and water consumption: influential factors in the metropolitan region of Barcelona». Urban Studies, $\mathrm{n}^{\circ}$ 43, 1.605-1.623.

DOMENE, E.; SAURÍ, D. y PARÉS, M. (2005): «Urbanization and sustainable resource use: the case of garden watering in the metropolitan region of Barcelona». Urban Geography, $\mathrm{n}^{\mathrm{o}} 268,520-535$.

DOMENECH, L. y SAURÍ, D. (2011): «A comparative appraisal of the use of rainwater harvesting in single and multifamily buildings of the Metropolitan Area of Barcelona (Spain): social experience, drinking water savings and economic costs». Journal of Cleaner Production, $\mathrm{n}^{\circ} 19,598-608$.

FLACK, J.E. y GREENBERG, J. (1987): «Public attitudes toward water conservation». Journal of the American Water Works Association, $\mathrm{n}^{\circ}$ 79, 46-51. 
GARCÍA ACOSTA, X. (2012): Nous procesos d'urbanització i consum d'aigua per a usos domèstics. Una exploració de relacions a l'àmbit gironí. Universitat de Girona. Tesis Doctoral.

GARCÍA ACOSTA, X. (2013): «Urbanizatzació difusa i consum d'aigua per a usos domèstics. Una exploració de relacions». Documents d'Anàlisis Geogràfica, vol. 59/2, 347-362.

GREGORY, G.D. y DI LEO, M. (2003): «Repeated behavior and environmental psychology: the role of personal involvement and habit formation in explaining water consumption», en Journal of Applied Social Psychology, $\mathrm{n}^{\circ} 33,1.261-1.296$.

HERNÁNDEZ, M. (2013): «Análisis de los procesos de transformación territorial en la provincia de Alicante (1985-2011) y su incidencia en el recurso hídrico a través del estudio bibliográfico». Documents d'Anàlisi Geogràfica, vol. 59/1, 105-136.

HERNÁNDEZ HERNÁNDEZ, M.; MORALES GIL, A. y SAURÍ PUJOL, D. (2014): «Ornamental plants and the production of nature(s) in the Spanish real estate and bust: the case of Alicante». Urban Geography. Disponible en: http://dx.doi.org/10.1080/0272 3638.2013.871813

HOFFMAN, M.; WORTHINGTON, A. y HIGGS, H. (2006): «Urban water demand with fixed volumetric charging in a large municipality: the case of Brisbane, Australia», en Australian Journal of Agricultural and Resource Economics, ${ }^{\circ}$ 50, 347-359.

HOPE, D.; GRIES, C.; ZHU, W.; FAGAN, W., REDMAN, C.L.; GRIMM, N.B., et al. (2003): «Socieconomics drive urban plant diversity». Proceedings of the National Academy of Science, $\mathrm{n}^{\circ} 100,8.788-8.792$.

HURD, B.H. (2006): «Water conservation and residential landscape: household preferences, household choices». Journal of Agricultural and Resource Economics, n ${ }^{\circ}$ 31, 21-32.

INE (INSTITUTO NACIONAL DE ESTADÍSTICA) (2012): Censos de población 2001 y 2011. Disponible en: http://www.ine.es/inebmenu/mnu_cifraspob.htm

KEIFFER, J.C. y DZIEGILEWSKI, B. (1991): Analysis of the Residential Landscape Irrigation in Southern California. Research Report prepared for Metropolitan Water District of Southern California. Los Angeles.

KIESLING, F.M. y MANING, C.M. (2010): «How green is your thumb? Environmental gardening identity and ecological gardening practices». Journal of Environmental Psychology, $\mathrm{n}^{\mathrm{o}} 30,315-327$.

LARSEN, L. y HARLAN, S.L. (2006): «Desert dreamscapes. Residential landscapes preference and behavior». Landscape and Urban Planning, $\mathrm{n}^{\circ}$ 78, 85-100.

LARSON, K.L. CASAGRANDE, D. HARLAN, S.L. y YABIKU, S.T. (2009): «Residents yard choices and rationales in a desert city: Social priorities, ecological impacts, and decision tradeoffs». Environmental Management, $\mathrm{n}^{\circ}$ 44, 921-937.

LEICHENKO, R.M. y SOLECKI, W.D. (2005): «Exporting the American Dream: the globalization of suburban consumption landscapes». Regional Studies, Vol. 39(2), 241-253.

LOH, M. y COGHLAN, P. (2003): Domestic water use study: Perth, Western Australia 1998-2001. Perth. Water Corporation.

MINISTERIO DE FOMENTO (2012): Viviendas visadas. Disponible en: http://www. fomento.gob.es/BE/?nivel=2\&orden=09000000

MUSTAFA, D. SMUCKER, T.A. GINN, F. JOHNS, R. y CONNELY, S. (2010): «Xeriscape people and the cultural politics of turfgrass transformation». Environment and Planning $D, \mathrm{n}^{\circ} 28,600-617$. 
NAUGES, C. y REYNAUD, A. (2001): «Estimation de la demande domestique d'eau potable en France», en Revue économique, n ${ }^{\circ}$ 52, 167-185.

NAUGES, C. y THOMAS, A. (2000): «Privately-operated water utilities, municipal price negotiation and estimation of residential water demand: The case of France», en Land Economics, $\mathrm{n}^{\circ} 76,68-85$.

PARÉS, M.; MARCH, H. y SAURI, D. (2013): «Atlantic gardens in Mediterranean climates: Understanding the production of suburban natures». International Journal of Urban and Regional Research, Vol. 37(1), 328-347.

PNUD (2000): Programa de Naciones Unidas para el Desarrollo. Disponible en: http://www. dicc.hegoa.ehu.es/listar/mostrar/170

ROVIRA, A. (Ed.) (2011): Atlas socio-comercial de la Comunitat Valenciana 2009. Valencia. Generalitat Valenciana y Consejo de Cámaras Oficiales de Comercio, Industria y Navegación de la Comunidad.

RENWICK, M.E. y ARCHIBALD, S.O. (1998): «Demand side management policies for residential water use: Who bears the conservation burden?» Land Economics, Vol. 74 (3), 343-359.

ROVIRA, A. (Ed.) (2011): Atlas socio-comercial de la Comunitat Valenciana 2009. Valencia, Generalitat Valenciana y Consejo de Cámaras Oficiales de Comercio, Industria y Navegación de la Comunidad Valenciana.

SIME, J. (1993): «What makes a house a home: the garden?. En: Bulos, M. y Teymur, N. (Eds.): Housing: Design, research, education. Avebury. Aldershot, 239-254.

ST. HILAIRE, R.; SPINTI, J.E.; VAN LEEUWEN, D. y SMITH, C. (2003): Lansdcape preferences and attitudes toward water conservation: A public opinion survey of homeowners in Las Cruces. New Mexico. New Mexico State University, Agricultural Experiment Station.

SWYNGEDOUW, E. (1999): «Modernity and hibridity: Nature, regeneracionismo, and the production of the Spanish waterscape, 1890-1930». Annals of the Association of American Geographers, Vol. 89 (3), 443-465.

SYME, G.J.; KANTOLA, S.J. y THOMAS, J.F. (1980): «Water resources and the quarter acre block». En: Thorne R. y Arden, S. (eds.): People and the Man Made Environment. Sydney. University of Sydney, 192-201.

SYME, G.J., SHAO, Q.; PO, M. y CAMPBELL, E. (2004): «Predicting and understanding home garden water use». Landscape and Urban Planning, $\mathrm{n}^{\circ}$ 68,121-128.

TIMMINS, C. (2002): «Measuring the dynamic efficiency costs of regulators preferences: municipal water utilities in the arid West», en Econometrica, n ${ }^{\circ} 70,603-629$.

TORRES, F.J. (1997): Ordenación del litoral en la Costa Blanca. Alicante. Publicaciones de la Universidad de Alicante, 269 p.

VERA, J.F. (1987): Turismo y urbanización en el litoral alicantino. Alicante. Diputación Provincial de Alicante, $441 \mathrm{p}$.

VIDAL, M.; DOMENE, E. y SAURÍ, D. (2011): «Changing geographies of water-related consumption: residential swimming pools in suburban Barcelona». Royal Geographical Society, vol. 43 (1), 67-75.

WENTZ, E. y GOBER, P. (2007): «Determinants of small-area water consumption for the city of Phoenix, Arizona», Water Resources Management, $\mathrm{n}^{\circ}$ 21, 1.849-1.863.

YABIKU, S.T; CASAGRANDE, D.G. y FARLEY-METZGER, E. (2008): «Preferences for landscape choice in a Southwestern desert city». Environment and Behaviour, n ${ }^{\circ} 40,382-400$. 